\title{
Seasonal variation in bioactive properties and phenolic composition of cardoon (Cynara cardunculus var. altilis) bracts
}

\author{
Filipa Mandim ${ }^{\mathrm{a}, \mathrm{b}}$, Spyridon A. Petropoulos ${ }^{\mathrm{c}, *}$, Maria Inês Dias ${ }^{\mathrm{a}}$, José Pinela ${ }^{\mathrm{a}}$, Marina Kostic ${ }^{\mathrm{d}}$, \\ Marina Soković $^{\mathrm{d}}$, Celestino Santos-Buelga ${ }^{\mathrm{b}}$, Isabel C.F.R. Ferreira ${ }^{\mathrm{a}}$, Lillian Barros ${ }^{\mathrm{a}, *}$ \\ ${ }^{a}$ Centro de Investigação de Montanha (CIMO), Instituto Politécnico de Bragança, Campus de Santa Apolónia, 5300-253 Bragança, Portugal \\ ${ }^{\mathrm{b}}$ Grupo de Investigación en Polifenoles (GIP-USAL), Facultad de Farmacia, Universidad de Salamanca, Campus Miguel de Unamuno s/n, 37007 Salamanca, Spain \\ ${ }^{\mathrm{c}}$ University of Thessaly, Department of Agriculture, Crop Production and Rural Environment, 38446, N. Ionia, Volos, Greece \\ ${ }^{\mathrm{d}}$ Institute for Biological Research "Siniša Stanković"- National Institute of Republic of Serbia, University of Belgrade, Bulevar Despota Stefana 142, 11000 Belgrade, Serbia
}

\section{A R T I C L E I N F O}

\section{Keywords:}

Cynara cardunculus

Phenolic compounds

Antioxidant/anti-inflammatory

Antimicrobial activity

Cytotoxic activity

Seasonal changes

Caffeoylquinic acid

\begin{abstract}
A B S T R A C T
Cardoon (Cynara cardunculus L.) bracts were collected at different maturation stages to investigate seasonal changes in the phenolic compounds profile and in vitro bioactivities. Among the 12 phenolic compounds tentatively identified, 3,5-O-dicaffeoylquinic acid $(21.83 \mathrm{mg} / \mathrm{g}$ extract) and apigenin-7-O-glucuronide (10.6 mg/g extract) were the most abundant. Immature bracts (C1: principal growth stage (PGS) 5) had the highest phenolic compounds content, and anti-inflammatory $\left(\mathrm{IC}_{50}=72 \mu \mathrm{g} / \mathrm{mL}\right)$ and cytotoxic $\left(\mathrm{GI}_{50}\right.$ of $\left.30-79 \mu \mathrm{g} / \mathrm{mL}\right)$ activities. Moreover, extract C1 inhibited efficiently the formation of thiobarbituric acid reactive substances (TBARS; $\mathrm{IC}_{50}=26.8 \mu \mathrm{g} / \mathrm{mL}$ ), while extract C8 (PGS 8/9) was more effective against oxidative haemolysis (IC ( $_{50} 38$ and $75 \mu \mathrm{g} / \mathrm{mL}$ ). The highest antibacterial and antifungal activities were attributed to samples C1 and C6 (PGS 7/8) and samples C2 (PGS 5/6) and C4 (PGS 6/7), respectively. Overall, the obtained results suggest the seasonal changes of polyphenolic composition and bioactivity of cardoon bracts of variable maturity.
\end{abstract}

\section{Introduction}

Mediterranean plant species are rich sources of phenolic compounds, an important class of phytochemicals with health-promoting effects, biosynthesized through the secondary plant metabolism (Ferreira, Morales, \& Barros, 2017; Pinela, Carvalho, \& Ferreira, 2017). Despite the existing knowledge of traditional medicine regarding preparation methods, dosages, and toxicity, as well as about the best conditions for culture and harvesting, the current scientific community seeks to broaden the knowledge regarding the bioactive potential of plant species and the impact that different pre- and post-harvest factors may have on bioactive properties (Ferreira et al., 2017; Li, Kong, Fu, Sussman, \& Wu, 2020). It is well-known that the plant development, metabolism and, consequently, the secondary metabolites biosynthesis is affected by the edaphoclimatic conditions of growing locations, such as the photoperiod and soil fertility, the air temperature and precipitation, and the agricultural practices (Li et al., 2020). Therefore, the study of the influence of these parameters on the chemical composition and biological potential of plant matrices is an essential contribution to maximize their potential and economic value, and to promote their valorisation through alternative uses in pharmaceutical, nutraceutical and food industries (Li et al., 2020; Martins, Barros, \& Ferreira, 2016).

Cardoon (Cynara cardunculus L.) is a member of the Asteraceae family, native to the Mediterranean basin. This species comprises three botanical varieties, the wild cardoon (var. sylvestris), the domesticated cardoon (var. altilis), and the globe artichoke (var. scolymus) (Gominho, Curt, Lourenço, Fernández, \& Pereira, 2018; Zayed, Serag, \& Farag, 2020). It is spread all over the world, except for the Antarctic continent, as a result of its ability to adapt to severe environmental conditions and abiotic stress factors, such as water stress, high salinity levels, temperature extremities, and low fertilized, stony and with variable $\mathrm{pH}$ soils (Conceição et al., 2016; Vergara, Ladero, García-Ochoa, \& Villar, 2018).

Cardoon has a long tradition, being used since the times of the ancient Egyptians, Greeks and Romans as food and medicine. It has also been widely used in the Mediterranean countries' recipes, as an ornamental crop, and in traditional medicine due to its known health benefits (de Falco, Incerti, Amato, \& Lanzotti, 2015; Gominho et al., 2018). In fact, this crop has been considered a functional food due to their bioactive properties. Several authors emphasized its capacity to reduce the inflammation and the lipid content, and its antioxidant, antimicrobial, hepatoprotective, anti-inflammatory, anticarcinogenic and

\footnotetext{
* Corresponding authors.

E-mail addresses: spetropoulos@uth.gr (S.A. Petropoulos), lillian@ipb.pt (L. Barros).
} 
bile-expelling effects (Gostin \& Waisundara, 2019; Petropoulos et al., 2019a; Scavo et al., 2019; Zayed et al., 2020). Moreover, this species has a significant economic impact due to the diverse industrial applications, representing also a rich source of several classes of compounds with important medicinal and functional properties. Examples of industrial applications include its clotting properties (proteases and proteolytic compounds) for the production of dairy products such as protected designation of origin (PDO) cheeses (Almeida \& Simões, 2018; Amira, Besbes, Attia, \& Blecker, 2017), for paper pulp production due to its high cellulose and hemicellulose content (Gominho et al., 2018; Ramos et al., 2014; Zayed et al., 2020), and for biomass and bioenergy production (Gominho et al., 2018; Zayed et al., 2020).

Apart from the current industrial applications described above, the valorisation of the medicinal properties of the species could substantially improve the added value of the crop. According to the literature, the medicinal value demonstrated by the different tissues of this multipurpose crop could be directly related to its composition in primary (e.g., vitamins, minerals, fibres, and inulin) and secondary (e.g., flavonoids, lignans, phenolic acids) metabolites, obtained with good yields particularly from bracts and flower stems (de Falco et al., 2015; Zayed et al., 2020). Cardoon bracts are a by-product that could be used for industrial purposes, since it is a rich source of bioactive compounds, namely phenolic acids and flavonoids that can be applied in food, pharmaceutical and cosmeceutical industries. Several studies have proven that the content and abundance in these metabolites are affected by pre-harvest factors such as agricultural practices, crop management, cultivar type, geographical location, plant tissues, and developmental stage (Conceição et al., 2016; Gominho et al., 2018; Pandino et al., 2017; Zayed et al., 2020). Lombardo et al., (2010) already reported the seasonal variation in the polyphenols content in capitulum parts such as bracts, floral stems, and receptacles in spring and winter. They also verified higher levels of phenolic compounds in the spring compared to other seasons, whereas some of the identified compounds were not detected in the samples collected in winter. However, more complete studies are needed to obtain a thorough profile of chemical composition and bioactive properties.

Despite the multi-purpose uses of cardoon, a significant amount of bio-waste is produced especially during the heads processing where bracts and other non-edible parts are discarded. Moreover, edibility of heads is rapidly reduced as maturation progresses meaning that a considerable portion of plant biomass remains in the field unexploited. The present study was carried out to evaluate the seasonal variations in the profile of phenolic compound and the in vitro bioactive potential of cardoon bracts collected from central Greece at different maturation stages in order to identify alternative uses of the generated bio-waste. A deeper knowledge about this Mediterranean species and the influence that specific factors such as the maturity stage have on its chemical composition and, consequently, on its bioactive potential is important to promote its adequate production and utilization, in order to take advantage of the full potential of this multi-purpose plant.

\section{Materials and methods}

\subsection{Plant material}

Bracts of Cynara cardunculus L. var. altilis (DC), cv. Bianco Avorio (Fratelli Ingegnoli Spa, Milano, Italy), were collected in the experimental field of the University of Thessaly in Velestino (22.756E, $39.396 \mathrm{~N}$ ), central Greece, during the growing period of 2017-2018. According to the Biologische Bundesanstalt, Bundessortenamt und Chemische Industrie (BBCH) scale, the principal growth stages of the samples (PGSs) were between 5 and 8/9. Bract samples were collected at eight harvest dates: $\mathrm{C} 1$ was collected at the end of April (PGS 5), C2 and C3 were collected at the beginning (PGS 5/6) and in the end (PGS 6) of May, respectively; C4 was collected at the beginning of June (PGS 6/7), the samples C5 and C6 were collected at the beginning (PGS 7) and at the end of July (PGS 7/8), respectively; finally, the samples C7 and C8 were collected at the beginning (PGS 8) and in the end of August (PGS 8/9), respectively.

All bract samples were freeze-dried (Sublimator model EKS, Christian Zirbus Co., Germany), reduced to a fine powder ( $\sim 20$ mesh) using a domestic electric blender, and homogenized to obtain representative samples, which were stored in air-sealed bags under deep freezing conditions $\left(-80^{\circ} \mathrm{C}\right)$ until further analysis.

\subsection{Extraction methodology}

The extraction methodology was performed according to the procedure previously described by Mandim et al. (2020b). The powdered bract samples $(1.5 \mathrm{~g})$ were extracted for $1 \mathrm{~h}$ at room temperature with $\mathrm{EtOH} / \mathrm{H}_{2} \mathrm{O}(80: 20, v / v, 30 \mathrm{~mL})$ under vigorous stirring (150 rpm). The mixture was then filtered through a Whatman No. 4 filter paper and concentrated at $40{ }^{\circ} \mathrm{C}$ under reduced pressure (rotary evaporator Büchi R-210, Flawil, Switzerland). The obtained aqueous phase was frozen and lyophilized (FreeZone 4.5, Labconco, Kansas City, MO, USA).

\subsection{Identification and quantification of phenolic compounds}

The obtained extracts were re-dissolved in $\mathrm{EtOH} / \mathrm{H}_{2} \mathrm{O}(20: 80, v / v)$ to obtain solutions at $10 \mathrm{mg} / \mathrm{mL}$ and then were filtered through $0.22 \mu \mathrm{m}$ nylon syringe filters. The phenolic compounds profile was determined by high-performance liquid chromatography coupled with diode array detection and electrospray ionization mass spectrometry (HPLC-DAD-ESI/MS), as previously described by Bessada et al. (2016). The comparison of the retention times and UV-vis and mass spectra with those of commercial standards and the available literature information allowed the tentative identification of phenolic compounds in the tested cardoon bract extracts. Quantification was performed by determining the peak area and using the calibration curves prepared for each available commercial standard (Extrasynthèse, Genay, France) based on the UV signal. The results were expressed in mg per $\mathrm{g}$ of extract.

\subsection{Evaluation of the biological potential}

\subsubsection{Antioxidant assessment}

The in vitro capacity of cardoon bracts to protect cell membranes from oxidation was measured through (i) the thiobarbituric acid reactive substances (TBARS) formation and (ii) the oxidative haemolysis (OxHLIA) inhibition assays. The synthetic antioxidant trolox (Fisher Scientific, Lisbon, Portugal) was used as a positive control in both assays.

The TBARS assay measures the extracts capacity to inhibit the formation of malondialdehyde and other TBARS and was performed using porcine (Sus scrofa) brain tissues as oxidizable substrate, following the procedure previously described by Mandim et al. (2020a). The cardoon bract extracts were re-dissolved in water to obtain a stock solution at $5 \mathrm{mg} / \mathrm{mL}$, further diluted to obtain the range of concentrations $(0.625-0.0048 \mathrm{mg} / \mathrm{mL})$ tested. The results were expressed as the extract concentration $\left(\mathrm{IC}_{50}, \mu \mathrm{g} / \mathrm{mL}\right.$ ) that causes $50 \%$ inhibition of the oxidation process.

The OxHLIA assay measures the extracts capacity to inhibit the oxidative haemolysis and was performed using erythrocytes isolated from sheep blood collected from healthy animals, following the procedure previously described by Mandim et al. (2019). The results were expressed as the extract concentration $\left(\mathrm{IC}_{50}, \mu \mathrm{g} / \mathrm{mL}\right.$ ) required to maintain the integrity of $50 \%$ of the erythrocyte population after 60 and $120 \mathrm{~min}$.

\subsubsection{Anti-inflammatory activity}

The anti-inflammatory activity was assessed by measuring the extracts' capacity to inhibit the lipopolysaccharide (LPS)-induced nitrite 
Table 1

Retention time (Rt), wavelengths of maximum absorption $\left(\lambda^{\max }\right)$ in the UV-vis region, mass spectral data, and tentative identification of the phenolic compounds identified in the hydroethanolic extracts of Cynara cardunculus bracts.

\begin{tabular}{|c|c|c|c|c|c|}
\hline Peak & Rt (min) & $\lambda^{\max }(\mathrm{nm})$ & {$[\mathrm{M}-\mathrm{H}]^{-}(m / z)$} & $\operatorname{MS}^{2}(m / z)$ & Tentative identification \\
\hline 1 & 7.06 & 325 & 353 & 191(100), 179(10), 161(5), 135(5) & 5-O-Caffeoylquinic acid \\
\hline 2 & 12.13 & 280 & 325 & 163(100), 145(5), 119(30) & $p$-Coumaric acid hexoside \\
\hline 3 & 16.11 & $285 / \operatorname{sh} 319$ & 463 & $287(100)$ & Eridictyol-O-glucuronide \\
\hline 4 & 16.82 & 317 & 367 & 193(7), 191(100), 173(5), 134(9) & 5-O-Feruloylquinic acid \\
\hline 5 & 17.98 & 335 & 593 & $285(100)$ & Kaempferol-3-O-rutinoside \\
\hline 6 & 18.57 & 343 & 461 & 285(100) & Luteolin-O-glucuronide \\
\hline 7 & 18.75 & 343 & 461 & $285(100)$ & Luteolin-O-glucuronide \\
\hline 8 & 19.93 & 340 & 447 & $285(100)$ & Luteolin- $O$-hexoside \\
\hline 9 & 20.43 & 324 & 515 & 353(50), 191(100), 179(15), 173(5), 135(5) & 3,5-O-Dicaffeoylquinic acid \\
\hline 10 & 22.92 & 337 & 445 & $269(100)$ & Apigenin-7-O-glucuronide \\
\hline 11 & 23.73 & 346 & 533 & 489(50), 447(5), 285(100) & Luteolin-O-malonyl-hexoside \\
\hline 12 & 28.09 & 332 & 517 & $473(100), 269(50)$ & Apigenin-malonyl-hexoside \\
\hline
\end{tabular}

oxide (NO) production by a murine macrophage cell line (RAW 264.7) as previously reported by Mandim et al. (2019). The extracts of cardoon bracts were re-dissolved in water to obtain a solution of $8 \mathrm{mg} / \mathrm{mL}$ that was diluted and tested. The commercial anti-inflammatory drug dexamethasone (Sigma-Aldrich, Saint Louis, MO, EUA) was used as a positive control, and samples without LPS (Sigma-Aldrich, Saint Louis, MO, EUA) were considered as the negative control. The results were expressed as the extract' concentration $\left(\mathrm{EC}_{50}, \mu \mathrm{g} / \mathrm{mL}\right.$ ) responsible for $50 \%$ of NO production inhibition.

\subsubsection{Cytotoxic and hepatotoxic activities}

The cytotoxic and hepatotoxic activities of the cardoon bract extracts $(6.25-400 \mu \mathrm{g} / \mathrm{mL}$ in water) were tested by the sulforhodamine B assay according to the procedure described by Barros et al. (2013). The cytotoxic potential was tested in four human tumour cell lines, namely cervical carcinoma - HeLa; hepatocellular carcinoma - HepG2, breast carcinoma - MCF-7, and non-small cell lung cancer - NCI-H460 (all acquired from the Leibniz-Institute DSMZ - German Collection of Microorganisms and Cell Cultures $\mathrm{GmbH}$ ). The hepatotoxic potential was evaluated in a non-tumour porcine liver primary culture - PLP2. Ellipticine (Sigma-Aldrich, St Louis, MO, USA) was used as a positive control and cell solution without any sample was the negative control. The results were expressed as the extract concentration $\left(\mathrm{GI}_{50}, \mu \mathrm{g} / \mathrm{mL}\right.$ ) needed for $50 \%$ of cell proliferation inhibition.

\subsubsection{Antimicrobial potential}

Cardoon bract extracts were re-dissolved in 5\% dimethyl sulfoxide (DMSO) (Sigma-Aldrich, Saint Louis, MO, EUA) and further diluted and tested following the procedure described by Petropoulos et al. (2019b). The antibacterial potential was assessed against the Gram-positive $\mathrm{Ba}$ cillus cereus (food isolate), Staphylococcus aureus (ATCC 6538) and Listeria monocytogenes (NCTC 7973), and the Gram-negative Escherichia coli (ATCC 35210), Enterobacter cloacae (human isolate), Salmonella Typhimurium (ATCC 13311). The antifungal potential was assessed against the micromycetes Aspergillus fumigatus (ATCC 1022), A. niger (ATCC 6275), A. versicolor (ATCC 11730), Penicillium funiculosum (ATCC 36839), P. ochrochloron (ATCC 9112), and P. aurantiogriseum ( $P$. verrucosum var. cyclopium (food isolate)). The microorganisms were provided by the Mycological laboratory, Department of Plant Physiology, Institute for Biological Research "Siniša Stanković" - National Institute of Republic of Serbia, University of Belgrade, Serbia. The commercial antibiotics ampicillin and streptomycin and the fungicides bifonazole and ketoconazole (all obtained from Sigma-Aldrich, St. Louis, MO, USA) were used as positive controls for the antibacterial and antifungal assays, respectively, while 5\% DMSO was used as negative control. The results were expressed as the minimal concentration (mg/ $\mathrm{mL}$ ) that inhibited the bacterial and fungal growth (MIC), and the minimal concentration $(\mathrm{mg} / \mathrm{mL})$ that killed the tested bacteria (MBC) and fungi (MFC) strains.

\subsection{Statistical analysis}

Three independent samples from each biological sample (bract samples) were tested, and all the assays were performed in triplicate. The results were presented as the mean value \pm standard deviation (except for antimicrobial activity). The statistical treatment was performed by the means of analysis of variance (ANOVA), while the Tukey's HSD test $(\alpha=0.05)$ was used to assess the significant differences between the samples (SPSS v. 26.0; IBM Corp., Armonk, New York). For the comparison between two samples, a two-tailed paired Student's $t$-test was applied to assess the statistical differences $(\alpha=0.05)$.

\section{Results and discussion}

\subsection{Polyphenolic composition}

The chromatographic information (retention time, $\lambda^{\max }$ of maximum absorption in the UV-vis region, pseudomolecular ion, and fragmentation pattern) regarding the identified phenolic compounds and their quantification is shown in Tables 1 and 2, respectively. Twelve phenolic compounds were tentatively identified, namely-four phenolic acid derivatives (peaks number 1, 2, 4 and 9) and eight flavone/ol glycosides $(3,5,6,7,8,10,11$ and 12). Fig. 1 shows a sample chromatogram of the reported phenolic compounds. Several reports have already described the phenolic profile of various cardoon tissues. Thus, the tentative identification of compounds with peak numbers $\mathbf{1}$, 2, 6, 7, 9 and 12 (5-O-caffeoylquinic acid, $p$-coumaric acid hexoside, luteolin-O-glucuronide, luteolin-O-glucuronide, 3,5-O-dicaffeoylquinic acid, and apigenin- $O$-malonyl-hexoside) has been previously reported in cardoon heads (Mandim et al., 2020a) and seeds (Mandim et al., 2020b). Peaks 3 and 10 (eriodictyol-O-glucuronide and apigenin-7-Oglucuronide, respectively) were previously found in cardoon inflorescences of Portuguese origin (Dias et al., 2018). In addition, peaks 4, 8, and 11 (5-O-feruloylquinic acid, luteolin-O-hexoside, and luteolin$O$-malonyl-hexoside) were previously identified in leaf blades of wild cardoon by Chihoub et al. (2019). Finally, peak 5 was tentatively identified as kaempferol-3-O-rutinoside according to the information described by Chahdoura et al. (2019); to the best of the authors' knowledge, this latter compound has not been previously identified in C. cardunculus tissues.

3,5-O-Dicaffeoylquinic acid (peak 9) and apigenin-7-O-glucuronide (peak 10) were present in all the studied cardoon bract samples, being in general the majority compounds $(0.119-21.83$ and $2.79-10.6 \mathrm{mg} / \mathrm{g}$ extract, respectively) (Table 2). Samples at early maturity stages (e.g. samples C1, C2, C3, C4 and C5, which correspond to PGSs of 5-7) presented higher concentration of phenolic acid derivatives than the plant tissues of late maturity (samples C6, C7, and C8), especially sample $\mathrm{C} 1$ which had the highest overall content in phenolic acids, 
Table 2

Concentration of phenolic compounds in the hydroethanolic extracts of Cynara cardunculus bracts collected at different maturity stages.

\begin{tabular}{|c|c|c|c|c|c|c|c|c|}
\hline \multirow[t]{2}{*}{ Peak } & \multicolumn{8}{|c|}{ Concentration (mg/g extract) } \\
\hline & $\mathrm{C} 1$ & $\mathrm{C} 2$ & C3 & C4 & C5 & C6 & C7 & $\mathrm{C} 8$ \\
\hline 1 & $6.362 \pm 0.003^{\mathrm{b}}$ & $6.0 \pm 0.1^{\mathrm{c}}$ & $7.04 \pm 0.05^{\mathrm{a}}$ & $4.80 \pm 0.01^{\mathrm{d}}$ & $3.924 \pm 0.001^{\mathrm{e}}$ & $0.82 \pm 0.01^{\mathrm{f}}$ & n.d. & n.d. \\
\hline 2 & $1.114 \pm 0.003^{a}$ & $0.462 \pm 0.001^{\mathrm{e}}$ & $0.52 \pm 0.01^{\mathrm{d}}$ & $0.98 \pm 0.01^{\mathrm{b}}$ & $0.47 \pm 0.01^{\mathrm{e}}$ & $0.73 \pm 0.01^{\mathrm{c}}$ & n.d. & n.d. \\
\hline 3 & $0.98 \pm 0.01^{\mathrm{a}}$ & $0.9 \pm 0.1^{\mathrm{b}}$ & $0.71 \pm 0.01^{\mathrm{d}}$ & $0.727 \pm 0.002^{c}$ & $0.5984 \pm 0.0002^{\mathrm{e}}$ & $0.54 \pm 0.02^{f}$ & n.d. & n.d. \\
\hline 4 & $0.42 \pm 0.01^{\mathrm{c}}$ & $0.440 \pm 0.004^{\mathrm{b}}$ & $0.389 \pm 0.002^{d}$ & $0.55 \pm 0.01^{\mathrm{a}}$ & $0.283 \pm 0.003^{\mathrm{e}}$ & $0.121 \pm 0.005^{f}$ & n.d. & n.d. \\
\hline 5 & $0.5930 \pm 0.0002^{a}$ & $0.540 \pm 0.002^{\mathrm{e}}$ & $0.579 \pm 0.003^{\mathrm{b}}$ & $0.558 \pm 0.002^{d}$ & $0.5632 \pm 0.0004^{c}$ & $0.51 \pm 0.01^{\mathrm{f}}$ & n.d. & n.d. \\
\hline 6 & $1.80 \pm 0.01^{\mathrm{c}}$ & $1.872 \pm 0.004^{\mathrm{b}}$ & $1.70 \pm 0.02^{\mathrm{d}}$ & $2.036 \pm 0.001^{a}$ & $1.30 \pm 0.01^{\mathrm{e}}$ & $0.97 \pm 0.04^{\mathrm{f}}$ & n.d. & n.d. \\
\hline 7 & $1.07 \pm 0.01^{\mathrm{a}}$ & $1.036 \pm 0.001^{\mathrm{b}}$ & $0.76 \pm 0.01^{\mathrm{d}}$ & $0.89 \pm 0.02^{\mathrm{c}}$ & $0.593 \pm 0.001^{\mathrm{e}}$ & $0.578 \pm 0.003^{f}$ & n.d. & n.d. \\
\hline 8 & n.d. & n.d. & n.d. & n.d. & n.d. & n.d. & $1.51 \pm 0.01 *$ & $0.89 \pm 0.01 *$ \\
\hline 9 & $21.83 \pm 0.08^{a}$ & $13.8 \pm 0.3^{\mathrm{b}}$ & $8.2 \pm 0.2^{\mathrm{d}}$ & $5.31 \pm 0.05^{\mathrm{e}}$ & $13.08 \pm 0.03^{c}$ & $1.577 \pm 0.002^{\mathrm{f}}$ & $0.39 \pm 0.01^{g}$ & $0.119 \pm 0.003^{h}$ \\
\hline 10 & $10.6 \pm 0.3^{\mathrm{a}}$ & $9.38 \pm 0.02^{\mathrm{b}}$ & $6.33 \pm 0.01^{d}$ & $7.04 \pm 0.07^{\mathrm{c}}$ & $2.9 \pm 0.1^{\mathrm{f}}$ & $4.1 \pm 0.2^{\mathrm{e}}$ & $4.9 \pm 0.1^{g}$ & $2.79 \pm 0.03^{\mathrm{f}}$ \\
\hline 11 & $1.20 \pm 0.01^{\mathrm{c}}$ & $1.265 \pm 0.003^{\mathrm{a}}$ & $0.86 \pm 0.02^{\mathrm{b}}$ & $0.683 \pm 0.003^{\mathrm{e}}$ & $0.6966 \pm 0.0001^{d}$ & $0.53 \pm 0.01^{\mathrm{f}}$ & n.d. & n.d. \\
\hline 12 & $0.979 \pm 0.002^{\mathrm{e}}$ & $1.177 \pm 0.004^{\mathrm{a}}$ & $1.02 \pm 0.01^{\mathrm{c}}$ & $1.075 \pm 0.004^{\mathrm{b}}$ & $0.999 \pm 0.003^{d}$ & $0.83 \pm 0.02^{\mathrm{f}}$ & n.d. & n.d. \\
\hline$\Sigma \mathrm{PA}$ & $29.73 \pm 0.08^{\mathrm{a}}$ & $20.7 \pm 0.2^{\mathrm{b}}$ & $16.1 \pm 0.2^{\mathrm{d}}$ & $11.65 \pm 0.07^{\mathrm{e}}$ & $17.76 \pm 0.01^{\mathrm{c}}$ & $3.250 \pm 0.003^{f}$ & $0.39 \pm 0.01^{g}$ & $0.119 \pm 0.003^{h}$ \\
\hline$\Sigma \mathrm{F}$ & $17.3 \pm 0.3^{\mathrm{a}}$ & $16.19 \pm 0.01^{\mathrm{b}}$ & $11.98 \pm 0.05^{\mathrm{d}}$ & $13.01 \pm 0.08^{c}$ & $7.6 \pm 0.1^{\mathrm{f}}$ & $8.03 \pm 0.08^{e}$ & $6.4 \pm 0.1^{g}$ & $3.68 \pm 0.04^{h}$ \\
\hline$\Sigma P C$ & $94.0 \pm 0.4^{\mathrm{a}}$ & $73.8 \pm 0.4^{\mathrm{b}}$ & $56.2 \pm 0.5^{c}$ & $49.31 \pm 0.02^{\mathrm{e}}$ & $50.8 \pm 0.2^{\mathrm{d}}$ & $22.6 \pm 0.2^{\mathrm{f}}$ & $6.8 \pm 0.2^{g}$ & $3.80 \pm 0.04^{h}$ \\
\hline
\end{tabular}

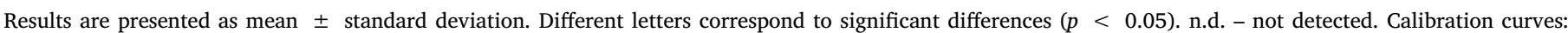

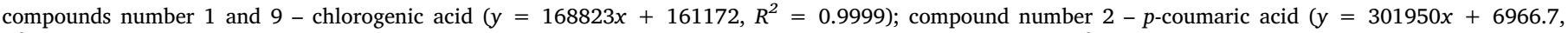

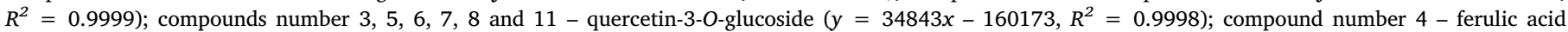

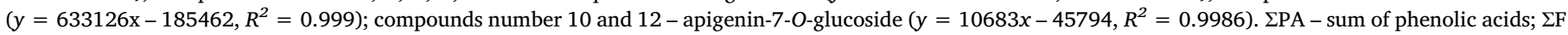
- sum of flavonoids; $\Sigma$ PC - sum of phenolic compounds. *Means statistical differences obtained by a $t$-student test $(p$-value $<0.01)$.

flavonoids and by extension in total phenolic compounds. Moreover, the content of total phenolic compounds decreased as maturation progressed and most of the identified compounds were not detected in samples with more advanced maturity (PSGs 8 and 8/9). In particular, in samples $\mathrm{C7}$ and $\mathrm{C}$, only luteolin- $\mathrm{O}$-hexoside, 3,5-O-dicaffeoylquinic acid, and apigenin-7-O-glucuronide were detected. This finding could be explained by the fact that hydroxycinnamates and derivatives are important precursors of the lignification process, which results in their degradation in favour of the lignin biosynthesis (Pandino et al., 2011). Therefore, the results of this study proved that the maturity stage influences not only the quantitative but also the qualitative profile of phenolic compounds present in cardoon bracts. Similar results were obtained for cardoon heads harvested during the flowering season
(Mandim et al., 2020b) and for globe artichoke bracts, floral stems, and receptacles, where the highest phenolic content was detected in samples collected during the spring and some of the identified compounds were not detected during the wintertime (Lombardo et al., 2010). Moreover, according to the study of Petropoulos, Pereira, Tzortzakis, Barros, \& Ferreira (2018) who tested the same plant material the total phenolic compounds content of bracts of $\mathrm{C} 1$ sample was higher than the other parts of plant (heads: $80 \mathrm{mg} / \mathrm{g}$; leaf blades: $63.2 \mathrm{mg} / \mathrm{g}$; leaf midribs and petioles: $24.4 \mathrm{mg} / \mathrm{g}$; seeds: $48.96 \mathrm{mg} / \mathrm{g}$ ). However, Conforti et al. (2008) who tested plant material collected from wild cardoon plants reported higher total phenolic compounds content in hydroalcoholic extracts of leaves and heads $(105 \mathrm{mg} / \mathrm{g}$ extract) than the bract extracts of our study. The study of Pandino et al. (2013) reported

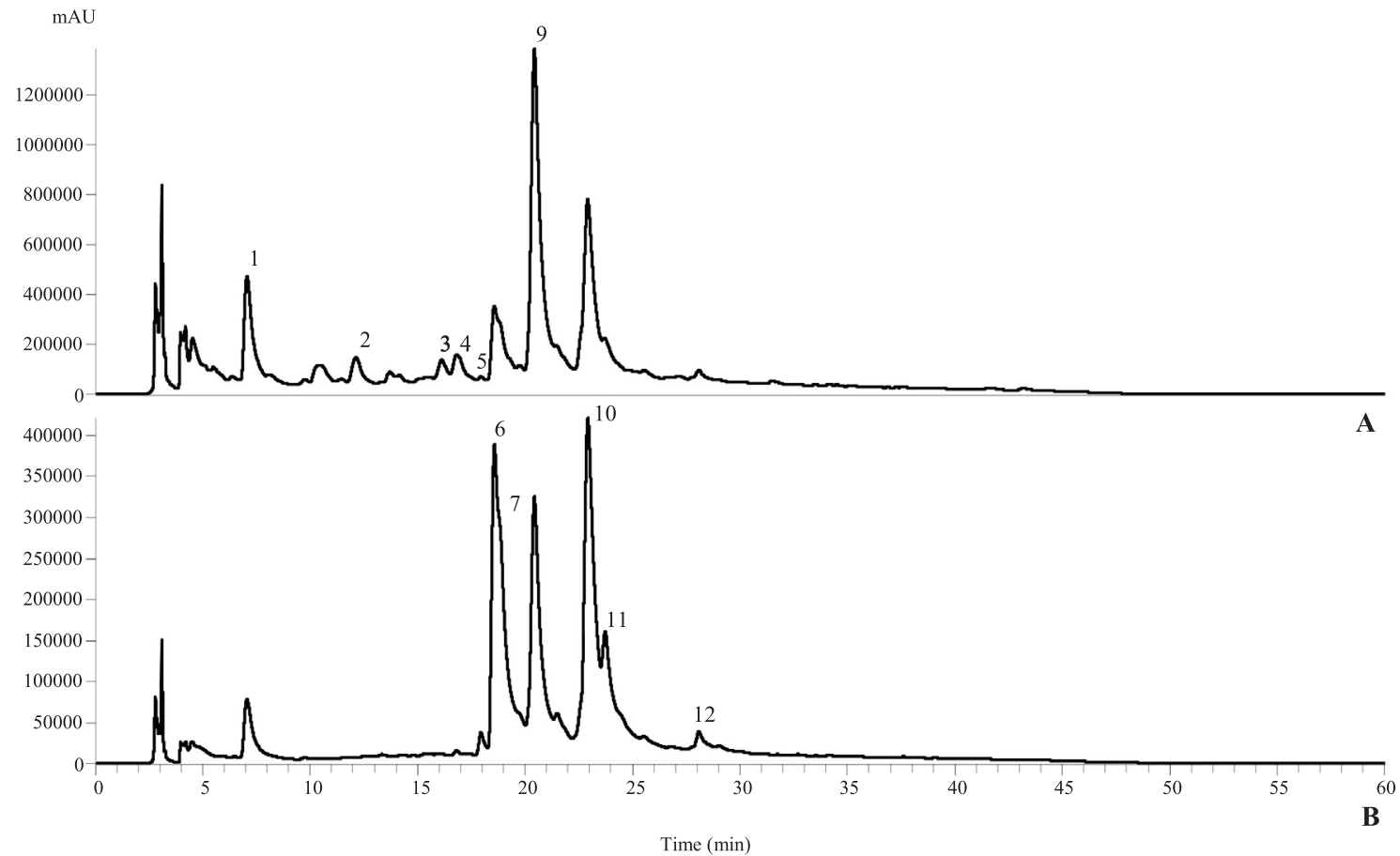

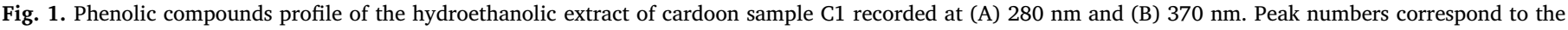
phenolic compounds identified in Table 1. 
Table 3

Antioxidant, cytotoxic and anti-inflammatory activities of the hydroethanolic extracts of Cynara cardunculus bracts collected at different maturity stages.

\begin{tabular}{|c|c|c|c|c|c|c|c|c|c|}
\hline & $\mathrm{C} 1$ & $\mathrm{C} 2$ & C3 & $\mathrm{C} 4$ & C5 & C6 & $\mathrm{C} 7$ & $\mathrm{C} 8$ & Positive control \\
\hline Antioxidant activity $\left(\mathrm{IC}_{50}, \mu \mathrm{g} / \mathrm{mL}\right)$ & & & & & & & & & Trolox \\
\hline TBARS formation inhibition & $26.8 \pm 0.1^{h}$ & $96 \pm 1^{f}$ & $148 \pm 1^{\mathrm{e}}$ & $260 \pm 3^{a}$ & $155 \pm 2^{d}$ & $212 \pm 1^{b}$ & $70 \pm 1^{g}$ & $164 \pm 6^{c}$ & $9.1 \pm 0.3$ \\
\hline OxHLIA, $\Delta t=60 \mathrm{~min}$ & $82 \pm 3^{d}$ & $219 \pm 9^{a}$ & $129 \pm 6^{c}$ & $131 \pm 5^{c}$ & $161 \pm 7^{\mathrm{b}}$ & $53 \pm 4^{e}$ & $38 \pm 3^{f}$ & $78 \pm 3^{d}$ & $21.2 \pm 0.7$ \\
\hline OxHLIA, $\Delta t=120 \mathrm{~min}$ & $159 \pm 3^{d}$ & $443 \pm 11^{\mathrm{a}}$ & $234 \pm 10^{\mathrm{c}}$ & $231 \pm 5^{c}$ & $325 \pm 10^{\mathrm{b}}$ & $252 \pm 19^{c}$ & $75 \pm 5^{e}$ & $38.3 \pm 0.4^{\mathrm{f}}$ & $41.1 \pm 0.8$ \\
\hline Cytotoxic activity $\left(\mathrm{GI}_{50}, \mu \mathrm{g} / \mathrm{mL}\right)$ & & & & & & & & & Ellipticine \\
\hline MCF-7 (breast adenocarcinoma) & $34 \pm 2^{d}$ & $251 \pm 2^{\mathrm{b}}$ & $302 \pm 12^{\mathrm{a}}$ & $196 \pm 10^{c}$ & $247 \pm 17^{\mathrm{b}}$ & $202 \pm 14^{\mathrm{c}}$ & $193 \pm 5^{a}$ & $>400$ & $1.21 \pm 0.02$ \\
\hline NCI-H460 (lung carcinoma) & $70 \pm 2^{e}$ & $216 \pm 15^{\mathrm{d}}$ & $>400$ & $277 \pm 18^{\mathrm{c}}$ & $367 \pm 14^{\mathrm{a}}$ & $313 \pm 8^{\mathrm{b}}$ & $>400$ & $>400$ & $0.9 \pm 0.1$ \\
\hline HeLa (cervical adenocarcinoma) & $30 \pm 2^{g}$ & $303 \pm 15^{\mathrm{b}}$ & $>400$ & $173 \pm 8^{\mathrm{f}}$ & $293 \pm 8^{c}$ & $243 \pm 5^{\mathrm{e}}$ & $252 \pm 7^{d}$ & $343 \pm 3^{a}$ & $1.03 \pm 0.09$ \\
\hline HepG2 (hepatocellular carcinoma) & $60 \pm 3^{g}$ & $249 \pm 10^{c}$ & $283 \pm 9^{a}$ & $172 \pm 5^{\mathrm{f}}$ & $271 \pm 19^{b}$ & $194 \pm 11^{\mathrm{e}}$ & $209 \pm 7^{d}$ & $265 \pm 8^{\mathrm{b}}$ & $1.10 \pm 0.09$ \\
\hline PLP2 (porcine liver primary cells) & $79 \pm 4^{d}$ & $>400$ & $>400$ & $218 \pm 18^{\mathrm{c}}$ & $276 \pm 12^{\mathrm{b}}$ & $288 \pm 13^{a}$ & $>400$ & $>400$ & $2.3 \pm 0.2$ \\
\hline $\begin{array}{l}\text { NO-production inhibition }\left(\mathrm{IC}_{50}, \mu \mathrm{g} /\right. \\
\mathrm{mL} \text { ) }\end{array}$ & & & & & & & & & Dexamethasone \\
\hline RAW 246.7 (murine macrophage cells) & $72 \pm 3^{f}$ & $>400$ & $>400$ & $187 \pm 15^{\mathrm{e}}$ & $233 \pm 12^{\mathrm{c}}$ & $199 \pm 14^{d}$ & $292 \pm 7^{b}$ & $304 \pm 11^{a}$ & $16 \pm 1$ \\
\hline
\end{tabular}

Results are expressed as the mean value \pm standard deviation. Different letters correspond to significant differences $(p<0.05)$. IC $C_{50}$ values correspond to the extract concentration needed to protect $50 \%$ of the erythrocyte from haemolysis in the oxidative haemolysis inhibition assay (OxHLIA), to provide $50 \%$ of antioxidant

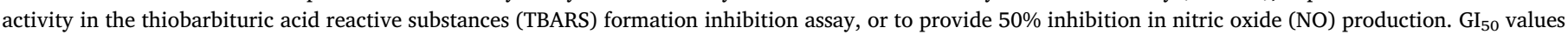
correspond to the extract concentration that causes $50 \%$ of cell inhibition.

that the receptacles have the highest content of phenolic compounds between February and April. Although the content of phenolic compounds is influenced by the maturity stage, parameters such as genetic background, plant tissue (e.g. blades, petioles and seeds) and seed viability also influence the chemical composition of the species (Dias et al., 2018; Mandim et al., 2020b; Petropoulos et al., 2018). However, further studies about the influence of pre- and post-harvest parameters are of great interest, as they may be useful for obtaining plant material with a high concentration of bioactive compounds or for regulating their chemical profile.

\subsection{Bioactive properties}

\subsubsection{Antioxidant assessment}

The evaluation of the antioxidant capacity of the hydroethanolic extracts of cardoon bracts was performed through two cell-based assays, and the obtained results are presented in Table 3. All the tested extracts revealed the ability to inhibit the oxidation process in both assays performed, although they revealed higher $\mathrm{IC}_{50}$ values than the used positive control, the commercial antioxidant Trolox. In general, for the TBARS assay, lower $\mathrm{IC}_{50}$ values (highest antioxidant potential) were demonstrated by samples of early maturity compared to the rest of the maturity stages tested; sample $\mathrm{C} 1$ revealed the lowest $\mathrm{IC}_{50}$ value, whereas samples of late maturity stage were the most effective in the OxHLIA assay, especially sample C8. Bracts collected at the principal growth stage (PGS) 6/7 (C4) were the ones that revealed the lower effectiveness against the lipid peroxidation compared to the rest of the tested maturity stages. While extract $C 2$ (PGS 5/6) revealed lower effectiveness to protect the erythrocytes from the haemolysis, exhibiting the highest $\mathrm{IC}_{50}$ values compared to the other maturity stages.

The measurement of the antioxidant potential of cardoon tissues, as well as of extracts obtained with different solvents and extraction procedures are widely described in the literature, mainly through the radical-scavenging capacity using the DPPH assay. Several authors already verified the interesting antioxidant potential of cardoon extracts; activity accomplished through different in vitro assays. Additionally, it has been reported that parameters such as the extraction methodology, the genetic information, the analysed plant tissue and the maturity stage of the plant significantly influence the antioxidant capacity (Mandim et al., 2020b; Petropoulos, Pereira, Barros, \& Ferreira, 2017; Petropoulos et al., 2018). In the study of Petropoulos et al. (2018), significant differences between the analysed cardoon parts (heads, seeds, leaf blades, leaf midribs, and petioles) were reported, with the hydromethanolic seed extract demonstrating the highest antioxidant activity. Compared to the same study, the antioxidant activity of bracts of $\mathrm{C} 1$ sample was higher than the other plant parts $\left(\mathrm{EC}_{50}\right.$ values of heads: $295 \mathrm{mg} / \mathrm{mL}$; leaf blades: $112 \mathrm{mg} / \mathrm{mL}$; leaf midribs and petioles: $964 \mathrm{mg} / \mathrm{mL}$; seeds: $125 \mathrm{mg} / \mathrm{mL}$ ) for the TBARS assay. In the study of Ramos et al. (2014), where the authors analysed the antioxidant potential of different cardoon plant parts (stalk outer and inner parts, capitula receptacle and bracts, and capitula florets), the authors attributed the greater activity to the outer stalk part, the capitula receptacle and the bracts. According to the literature information, the antioxidant activity is often linked with the content of polyphenols, although other compounds may also contribute to the overall antioxidant potential (Petropoulos et al., 2018). In the present study, the lower $\mathrm{IC}_{50}$ values in the TBARS formation inhibition assay were obtained from the sample with the highest content in phenolic compounds (C1) compared to the rest of the maturity stages tested, which suggest a positive correlation between these two parameters (phenolic compounds content and TBARS formation inhibition), whereas the same correlation was not verified for the OxHLIA assay, suggesting that other bioactive compounds may be involved in the demonstrated antioxidant potential.

The results obtained with the TBARS and OxHLIA assays performed in this study highlight potential biological and technological applications of the cardoon bracts in different industrial sectors. This cardoon by-product may be used in the development of bio-based ingredients to be applied as food preservatives to prevent the oxidation of fats and the formation of degradation products related to the so-called rancid flavour, since the capacity of the tested extracts to inhibit lipid peroxidation phenomena through the formation of TBARS (such as malondialdehyde) was demonstrated in vitro. On the other hand, such biobased ingredients could also be useful in the formulation of functional foods and nutraceuticals, among other products with health-promoting effects, due to their capacity to eliminate free radicals present in the human body and thus to protect against oxidative stress, since the peroxyl radicals generated in the OxHLIA assay system by the free-radical initiator APPH are also found in in vivo models.

\subsubsection{Cytotoxicity to tumour and non-tumour cells}

The results regarding the cytotoxic activity of cardoon bracts are presented in Table 3 as the extract concentration responsible for $50 \%$ of cell proliferation inhibition; thus, lower $\mathrm{GI}_{50}$ values indicate higher cytotoxic potential. The four tumour cell lines tested were selected based on the fact they are relevant models for the most common causes of cancer death worldwide. The extracts obtained from bracts of early maturity (C1) exhibited lower $\mathrm{GI}_{50}$ values $(30-79 \mu \mathrm{g} / \mathrm{mL}$ ) compared to other maturity stages, and therefore higher cytotoxic activity against all the tested cell lines. Among the tested cell lines, the lung carcinoma 
Table 4

Antimicrobial activity of the hydroethanolic extracts of Cynara cardunculus bracts collected at different maturity stages.

\begin{tabular}{|c|c|c|c|c|c|c|c|c|c|c|c|c|c|c|c|c|c|c|c|c|}
\hline \multirow[b]{2}{*}{$\begin{array}{l}\text { Antibacterial activity (mg/ } \\
\mathrm{mL} \text { ) }\end{array}$} & \multicolumn{2}{|l|}{$\mathrm{C} 1$} & \multicolumn{2}{|l|}{$\mathrm{C} 2$} & \multicolumn{2}{|l|}{ C3 } & \multicolumn{2}{|l|}{$\mathrm{C} 4$} & \multicolumn{2}{|l|}{ C5 } & \multicolumn{2}{|l|}{ C6 } & \multicolumn{2}{|l|}{ C7 } & \multicolumn{2}{|l|}{ C8 } & \multicolumn{2}{|c|}{ Streptomycin } & \multicolumn{2}{|c|}{ Ampicillin } \\
\hline & MIC & MBC & MIC & MBC & MIC & MBC & MIC & MBC & MIC & MBC & MIC & MBC & MIC & MBC & MIC & MBC & MIC & MBC & MIC & MBC \\
\hline Bacillus cereus & 1.58 & 3.16 & 1.56 & 1.56 & 0.78 & 1.56 & 1.57 & 1.57 & 3.37 & 3.37 & 0.81 & 1.61 & 1.18 & 2.36 & 0.87 & 1.73 & 0.1 & 0.2 & 0.25 & 0.4 \\
\hline Staphylococcus aureus & 1.58 & 3.16 & 3.12 & 6.24 & 3.12 & 6.24 & 3.15 & 3.15 & 3.37 & 6.75 & 3.22 & 6.45 & 4.73 & 9.46 & 1.73 & 2.33 & 0.04 & 0.1 & 0.25 & 0.45 \\
\hline Listeria monocytogenes & 3.16 & 6.33 & 3.12 & 6.24 & 3.12 & 6.24 & 3.15 & 6.3 & 3.37 & 6.75 & 1.61 & 3.22 & 1.61 & 3.22 & 1.73 & 2.33 & 0.2 & 0.3 & 0.4 & 0.5 \\
\hline Enterobacter cloacae & 3.16 & 6.33 & 3.12 & 6.24 & 3.12 & 6.24 & 3.15 & 6.3 & 1.69 & 3.37 & 1.61 & 3.22 & 4.73 & 9.46 & 1.73 & 2.33 & 0.2 & 0.3 & 0.25 & 0.5 \\
\hline Escherichia coli & 1.58 & 3.16 & 1.56 & 3.12 & 1.56 & 3.12 & 1.57 & 3.15 & 1.69 & 3.37 & 3.22 & 6.45 & 2.36 & 4.73 & 0.87 & 1.73 & 0.2 & 0.3 & 0.4 & 0.5 \\
\hline \multirow[t]{2}{*}{ Salmonella Typhimurium } & 1.58 & 3.16 & 3.12 & 6.24 & 3.12 & 6.24 & 3.15 & 6.3 & 1.69 & 3.37 & 3.22 & 6.45 & 4.73 & 9.46 & 3.46 & 6.92 & 0.2 & 0.3 & 0.75 & 1.2 \\
\hline & & & & & & & & & & & & & & & & & \multicolumn{2}{|c|}{ Ketoconazole } & \multicolumn{2}{|c|}{ Bifonazole } \\
\hline Antifungal activity (mg/mL) & MIC & MFC & MIC & MFC & MIC & MFC & MIC & MFC & MIC & MFC & MIC & MFC & MIC & MFC & MIC & MFC & MIC & MFC & MIC & MFC \\
\hline Aspergillus fumigatus & 4.22 & 8.44 & 0.52 & 1.04 & 0.78 & 3.12 & 0.52 & 1.05 & 1.12 & 2.25 & 0.54 & 1.07 & 0.88 & 1.75 & 3.50 & 7.00 & 0.25 & 0.5 & 0.15 & 0.2 \\
\hline Aspergillus versicolor & 1.05 & 2.11 & 0.26 & 0.52 & 0.78 & 1.56 & 0.26 & 0.52 & 0.56 & 1.125 & 0.54 & 1.07 & 0.88 & 1.75 & 1.75 & 3.50 & 0.2 & 0.5 & 0.1 & 0.2 \\
\hline Aspergillus niger & 8.44 & $>8.44$ & 1.04 & 2.08 & 1.56 & 3.12 & 0.525 & 1.05 & $>9$ & $>9$ & 1.07 & 2.15 & 1.75 & 3.50 & 1.75 & 3.50 & 0.2 & 0.5 & 0.15 & 0.2 \\
\hline Penicillium funiculosum & 1.05 & 2.11 & 0.52 & 1.04 & 6.24 & $>6.24$ & 0.52 & 1.05 & 0.56 & 1.12 & 0.27 & 0.54 & 3.50 & 7.00 & 1.75 & 3.50 & 0.2 & 0.5 & 0.2 & 0.25 \\
\hline Penicillium ochrochloron & 1.05 & 2.11 & 0.52 & 1.04 & 1.56 & 3.12 & 0.52 & 1.05 & 0.56 & 1.12 & 0.54 & 1.07 & 1.75 & 3.50 & 0.88 & 1.75 & 1 & 1.5 & 0.2 & 0.25 \\
\hline $\begin{array}{l}\text { Penicillium verrucosum var. } \\
\text { cyclopium }\end{array}$ & 1.05 & 2.11 & 0.52 & 1.04 & 6.24 & $>6.24$ & 0.52 & 1.05 & 0.56 & 1.12 & 0.27 & 0.54 & 0.88 & 1.75 & 0.88 & 1.75 & 0.2 & 0.3 & 0.1 & 0.2 \\
\hline
\end{tabular}

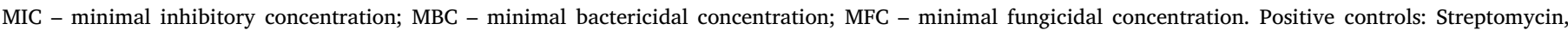
ampicillin, ketoconazole and bifonazole.

cells (NCI-H460) were those revealing lower susceptibility to the bract extracts compared to the rest of the tested cell lines; in addition, samples C3, C7 and C8 showed no activity against this tumour cell line ( $\mathrm{GI}_{50}$ values $>400 \mu \mathrm{g} / \mathrm{mL}$ ), whereas the extracts $\mathrm{C} 2$, C4, C5, and C6 had $\mathrm{GI}_{50}$ values lower than $400 \mu \mathrm{g} / \mathrm{mL}$ against the lung carcinoma cell line (NCI-H460) indicating mild toxic effects. In turn, $\mathrm{GI}_{50}$ values ranging from 79 ( $\mathrm{C} 1$ sample) to $>400 \mu \mathrm{g} / \mathrm{mL}$ were obtained against nontumour porcine liver primary cells (Table 3 ), although half of the tested extracts did not show hepatotoxicity at the tested concentrations. These results highlight the potential use of cardoon bracts in the development of new drugs and pharmaceuticals with antitumor properties.

The study performed by Mandim et al. (2020b) assessed the influence of the maturation process on the cytotoxic properties of cardoon capitula (heads). As observed for bract extracts, the extracts of cardoon heads of early maturity had also higher cytotoxic potential than heads of late maturity. The influence of other parameters such as the genetic background, the viability of the seeds, and the plant part on cytotoxic effects were already studied. According to Petropoulos et al. (2019b), a substantial inhibition capacity depending on the tested genotype was observed, since only some of the studied genotypes had some cytotoxic potential $\left(\mathrm{GI}_{50}\right.$ values from 212 to $>400 \mu \mathrm{g} / \mathrm{mL}$ ), while the extracts of immature bracts of our study (C1 sample) exhibited higher activity than the tested seeds. On the other hand, the seeds viability did not demonstrate any influence on the cytotoxic potential, since none of the tested extracts had activity $\left(\mathrm{GI}_{50}>400 \mu \mathrm{g} / \mathrm{mL}\right.$ ) (Mandim et al., 2020b). Compared to the most commonly used parts of the plant (heads and leaves), Conforti et al. (2008) suggested significant antiproliferative activity of hydroalcoholic extracts against various cancer cell lines, including human breast cancer cells (MCF-7 cell line) where the extracts of immature bracts (C1 sample) were similarly effective in our study. According to Ramos et al. (2017), the lipophilic extracts of cardoon leaves revealed higher anti-proliferative capacity than florets against the triple-negative breast cancer MDA-MB-231 cell line. They also suggested that the presence of high contents of cynaropicrin may be the principal responsible for the obtained results.

Regarding the variable (absent or low) toxicity to non-tumour cells, the obtained results are in agreement with other reports (Mandim et al., 2020a, 2020b; Petropoulos et al., 2019b, 2018).

\subsubsection{Anti-inflammatory activity}

The anti-inflammatory potential was evaluated through the ability of the extracts to inhibit the production of the proinflammatory mediator NO by the LPS-stimulated murine macrophage cell line (RAW 146.7). The concentration of cardoon bracts hydroethanolic extract responsible for inhibiting the NO production by $50 \%$ is shown in Table 3. Most of the samples revealed anti-inflammatory potential,

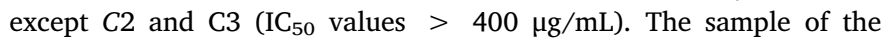
earliest maturity stage (C1) exhibited the highest anti-inflammatory ability with the lowest $\mathrm{IC}_{50}$ value $(72 \mu \mathrm{g} / \mathrm{mL})$. Although reports regarding the anti-inflammatory potential of cardoon tissues are very scarce, the obtained results are in agreement with the literature information. In the study of Mandim et al. (2020b), the cardoon capitula of early maturity revealed higher anti-inflammatory potential than the rest of the tested maturity stages through the same cell-based assay used in the present work. The NO production inhibition capacity of viable and non-viable cardoon seeds was also evaluated and none of the extracts revealed activity (Mandim et al., 2020b). On the other hand, Kammoun et al. (2010) measured the anti-inflammatory activity of leaf and stem extracts by the inhibition capacity of mammalian non-pancreatic phospholipases A2 (hG-IIA) and attributed higher potential to the leaves compared to the stems. Also, Salem et al. (2017) tested the anti-inflammatory potential of cardoon leaf extracts through the in vivo experimental Carr model and verified that the ethanolic extracts had capacity to inhibit the production of inflammatory mediators such as serotonin, histamine, and prostaglandin. To the best of the authors' knowledge, this is the first study evaluating the influence of the maturity stage of cardoon bracts on their anti-inflammatory potential using this cell-based assay.

\subsubsection{Antimicrobial activity}

The antibacterial and antifungal activities of cardoon bracts were evaluated against foodborne pathogens, including six bacterial and six fungi strains. The minimal inhibitory (MIC), bactericidal (MBC), and fungicidal (MFC) concentrations are presented in Table 4. All the extracts revealed bacteriostatic and bactericidal activity. In general, Gram-positive bacteria had higher susceptibility than the Gram-negative strains. This result is in agreement with the literature information, since Gram-positive bacteria are more vulnerable than Gram-negative bacteria as a result of the characteristics of their membrane (Mandim et al., 2020b; Scavo et al., 2019). Bacillus cereus, a rod-shaped spore forming bacteria commonly found in foods, was the more susceptible microorganism (MIC values between 0.78 and $3.37 \mathrm{mg} / \mathrm{mL}$ ), while Salmonella Typhimurium, one of the most common serovar of Salmonella, was the most resistant (MIC values between 1.58 and $4.73 \mathrm{mg} /$ $\mathrm{mL}$ ). None of the tested extracts revealed stronger activity than the commercial antibiotics used as positive controls, namely streptomycin and ampicillin. Extracts $\mathrm{C} 1$ and $\mathrm{C} 6$ showed the highest antibacterial activity, with the lowest MIC values ranging from 0.81 to $3.22 \mathrm{mg} / \mathrm{mL}$. 
In general, the analysed extracts of cardoon bracts presented lower MIC and MBC values than those obtained from extracts of capitula (Mandim et al., 2020b), inflorescences of different genotypes (Dias et al., 2018), and viable and non-viable seeds (Mandim et al., 2020b). A significant antibacterial activity was also described by Petropoulos et al. (2019b), who analysed methanolic extracts of seeds from different cardoon genotypes, suggesting a genotype effect.

The antifungal potential of cardoon bracts was also studied. The obtained MIC and MFC values are presented in Table 4. The extracts $C 2$ and C4 were those exhibiting the lowest MIC values (between 0.26 and $1.04 \mathrm{mg} / \mathrm{mL}$ ) and, consequently, the highest antifungal potential. On the other hand, samples C1 and C3 revealed the lower antifungal activity than the rest of the tested maturity stages, with the highest MIC values (between 0.78 and $8.44 \mathrm{mg} / \mathrm{mL}$ ). The antifungal potential of cardoon has already been proven, with reports attributing significant antifungal activity to different cardoon tissues, including inflorescences, seeds, heads, leaves, and rhizomes (Falleh et al., 2008; Petropoulos et al., 2019b; Scavo et al., 2019). In a recent study by the authors, the hydroethanolic extracts of cardoon bracts revealed lower MIC and MFC values (highest antifungal activity) when compared with the extracts of cardoon heads (Mandim et al., 2020b). In addition to the fact that the cardoon maturity stage affects the antifungal potential (Mandim et al., 2020b), also the genetic background (Dias et al., 2018; Petropoulos et al., 2018) and the analysed plant tissue (Petropoulos et al., 2018) have an impact on this activity.

Overall, the biological potential of cardoon bracts was strongly influenced by the developmental stage. This information can contribute to increase the economic value of this multi-purpose crop through a more detailed knowledge and the proper use of its bracts.

\section{Conclusion}

Cardoon bracts have received less use than other parts of the plant and are usually discarded as by-products through the industrial or domestic processing. Therefore, it is important to promote their valorisation and contribute to an adequate use which also decrease the amount of bulky by-products of the agro-industry and increase the added value of cardoon crop. According to our results, the content of phenolic compounds in bracts decreased with the maturation process. Dicaffeoylquinic acid and flavone glycosides, especially apigenin derivatives, were the major detected compounds. Bracts collected at the earliest stage of maturity (C1) stood out exhibiting the highest polyphenols content. The same sample (C1) also presented a higher capacity to inhibit the lipid peroxidation, the tumour cells proliferation, and the NO production compared to the rest of the tested maturation stages, suggesting a positive correlation of these activities with polyphenols content. On the other hand, the greater capacity to inhibit the oxidative haemolysis was recorded for the sample collected at a more advanced maturation stage (C8), pointing to the involvement of other bioactives in this effect, as those samples showed the lowest polyphenol content and diversity. Moreover, all the tested extracts were able to inhibit in some extent the bacterial and fungi growth; $\mathrm{C} 1$ and $\mathrm{C} 6$ samples revealed the best antibacterial results, while $C 2$ and $\mathrm{C} 4$ had the highest antifungal activity. Thus, this study highlighted the biological and chemical potential of cardoon bracts and the influence that the development stage has on those parameters. This by-product could be used in the development of bio-based ingredients with high potential as food preservatives (mainly due to their antioxidant and antimicrobial activities), additives for functional foods and nutraceuticals, as well as in new pharmaceutical formulations with anti-inflammatory and anti-tumour potential.

\section{CRediT authorship contribution statement}

Filipa Mandim: Methodology, Investigation, Writing - original draft. Spyridon A. Petropoulos: Methodology, Writing - review \& editing. Maria Inês Dias: Methodology. José Pinela: Methodology, Writing - original draft. Marina Kostic: Methodology. Marina Soković: Methodology. Celestino Santos-Buelga: Conceptualization, Methodology, Writing - review \& editing. Isabel C.F.R. Ferreira: Conceptualization, Methodology, Writing - review \& editing. Lillian Barros: Conceptualization, Methodology, Writing - review \& editing.

\section{Declaration of Competing Interest}

The authors declare that they have no known competing financial interests or personal relationships that could have appeared to influence the work reported in this paper.

\section{Acknowledgements}

The authors are grateful to the Foundation for Science and Technology (FCT, Portugal) for financial support by national funds FCT/MCTES to CIMO (UIDB/00690/2020). National funding by FCT, through the institutional scientific employment program-contract with M.I. Dias, J. Pinela, and L. Barros. To FCT for the PhD grant (SFRH/BD/ $146614 / 2019)$ of F. Mandim. The authors are also grateful to FEDERInterreg España-Portugal programme for financial support through the project 0377_Iberphenol_6_E; to the project TRANSCoLAB (0612_TRANS_CO_LAB_2_P), and to the Ministry of Education, Science and Technological Development of the Republic of Serbia (451-03-68/ 2020-14/200007).

\section{References}

Almeida, C. M., \& Simões, I. (2018). Cardoon-based rennets for cheese production. Applied Microbiology and Biotechnology, 102(11), 4675-4686.

Amira, A. B., Besbes, S., Attia, H., \& Blecker, C. (2017). Milk-clotting properties of plant rennets and their enzymatic rheological, and sensory role in cheese making: A review. International Journal of Food Properties, 28(51), 576-593.

Barros, L., Pereira, E., Calhelha, R. C., Dueñas, M., Carvalho, A. M., Santos-Buelga, C., \& Ferreira, I. C. F. R. (2013). Bioactivity and chemical characterization in hydrophilic and lipophilic compounds of Chenopodium ambrosioides L. Journal of Functional Foods, 5(4), 1732-1740.

Bessada, S. M. F., Barreira, J. C. M., Barros, L., Ferreira, I. C. F. R., \& Oliveira, M. B. P. P. (2016). Phenolic profile and antioxidant activity of Coleostephus myconis (L.) Rchb.f. An underexploited and highly disseminated species. Industrial Crops and Products, 89, 45-51.

Chahdoura, H., Barreira, J. C. M., Barros, L., Dias, M. I., Calhelha, R. C., Flamini, G., ... Ferreira, I. C. F. R. (2019). Bioactivity, hydrophilic, lipophilic and volatile compounds in pulps and skins of Opuntia macrorhiza and Opuntia microdasys fruits. $L W T$ Food Science and Technology, 105, 57-65.

Chihoub, W., Dias, M. I., Barros, L., Calhelha, R. C., Alves, M. J., Harzallah-Skhiri, F., \& Ferreira, I. C. F. R. (2019). Valorisation of the green waste parts from turnip, radish and wild cardoon: Nutritional value, phenolic profile and bioactivity evaluation. Food Research International, 126, Article 108651.

Conceiç̃o, C., Martins, P., Alvarenga, N., Dias, J., Lamy, E., Garrido, L., ... Duarte, M. F. (2016). Cynara cardunculus: Use in cheesemaking and pharmaceutical applications. In N. Koca (Vol. Ed.), Technological Approaches for Novel Applications in Dairy Processing: Vol. 1, (pp. 73-107). IntechOpen.

Conforti, F., Loele, G., Statti, G. A., Marrelli, M., Ragno, G., \& Menichini, F. (2008). Antiproliferative activity against human tumor cell lines and toxicity test on Mediterranean dietary plants. Food and Chemical Toxicology, 46, 3325-3332.

de Falco, B., Incerti, G., Amato, M., \& Lanzotti, V. (2015). Artichoke: Botanical, agronomical, phytochemical, and pharmacological overview. Phytochemistry Reviews, 14(6), 993-1018.

Dias, M. I., Barros, L., Barreira, J. C. M., Alves, M. J., Barracosa, P., \& Ferreira, I. C. F. R. (2018). Phenolic profile and bioactivity of cardoon (Cynara cardunculus L.) inflorescence parts: Selecting the best genotype for food applications. Food Chemistry, 268, 196-202.

Falleh, H., Ksouri, R., Chaieb, K., Karray-Bouraoui, N., Trabelsi, N., Boulaaba, M., \& Abdelly, C. (2008). Phenolic composition of Cynara cardunculus L. organs, and their biological activities. Comptes Rendus - Biologies, 331(5), 372-379.

Ferreira, I. C. F. R., Morales, P., \& Barros, L. (2017). The increasing demand for functional foods. In I. C. F. R. Ferreira, P. Morales, \& L. Barros (Eds.). Wild Plants, Mushrooms and Nuts: Functional Food Properties and Applications (pp. 1-10). John Wiley Sons Ltd.

Gominho, J., Curt, M. D., Lourenço, A., Fernández, J., \& Pereira, H. (2018). Cynara cardunculus L. as a biomass and multi-purpose crop: A review of 30 years of research. Biomass and Bioenergy, 109, 257-275.

Gostin, A. I., \& Waisundara, V. Y. (2019). Edible flowers as functional food: A review on artichoke (Cynara cardunculus L.). Trends in Food Science and Technology, 86, 381-391. 
Kammoun, M., Koubaa, I., Ali, Y. B., Jarraya, R., Gargouri, Y., Damak, M., \& Bezzine, S. (2010). Inhibition of pro-inflammatory secreted phospholipase A2 by extracts from Cynara cardunculus L. Applied Biochemistry and Biotechnology, 162, 662-670.

Li, Y., Kong, D., Fu, Y., Sussman, M. R., \& Wu, H. (2020). The effect of developmental and environmental factors on secondary metabolites in medicinal plants. Plant Physiology and Biochemistry, 148, 80-89.

Lombardo, S., Pandino, G., Mauromicale, G., Knödler, M., Carle, R., \& Schieber, A. (2010). Influence of genotype, harvest time and plant part on polyphenolic composition of globe artichoke [Cynara cardunculus L. var. scolymus (L.) Fiori]. Food Chemistry, 119(3), 1175-1181.

Mandim, F., Barros, L., Calhelha, R. C., Abreu, R. M. V., Pinela, J., Alves, M. J., ... Ferreira, I. C. F. R. (2019). Calluna vulgaris (L.) Hull: Chemical characterization, evaluation of its bioactive properties and effect on the vaginal microbiota. Food and Function, 10, $78-89$.

Mandim, F., Dias, M. I., Pinela, J., Barracosa, P., Ivanov, M., \& Ferreira, I. C. F. R. (2020a). Chemical composition and in vitro biological activities of cardoon (Cynara cardunculus L. var. altilis DC.) seeds as influenced by viability. Food Chemistry, 323, Article 126838.

Mandim, F., Petropoulos, S. A., Giannoulis, K. D., Dias, M. I., Fernandes, Â., Pinela, J., ... Ferreira, I. C. F. R. (2020b). Seasonal variation of bioactive properties and phenolic composition of Cynara cardunculus var. altilis. Food Research International, 134, Article 109281.

Martins, N., Barros, L., \& Ferreira, I. C. F. R. (2016). In vivo antioxidant activity of phenolic compounds: Facts and gaps. Trends in Food Science \& Technology, 48, 1-12.

Pandino, G., Lombardo, S., Mauromicale, G., \& Williamson, G. (2011). Profile of polyphenols and phenolic acids in bracts and receptacles of globe artichoke (Cynara cardunculus var. scolymus) germplasm. Journal of Food Composition and Analysis, 24(2), 148-153.

Pandino, G., Lombardo, S., Antonino, L. M., Ruta, C., \& Mauromicale, G. (2017). In vitro micropropagation and mycorrhizal treatment influences the polyphenols content profile of globe artichoke under field conditions. Food Research International, 99, 385-392.

Pandino, G., Lombardo, S., Lo Monaco, A., \& Mauromicale, G. (2013). Choice of time of harvest influences the polyphenol profile of globe artichoke. Journal of Functional Foods, 5(4), 1822-1828.

Petropoulos, S. A., Fernandes, Â., Pereira, C., Tzortzakis, N., Vaz, J., Soković, M., ... Ferreira, I. C. F. R. (2019b). Bioactivities, chemical composition and nutritional value of Cynara cardunculus L. seeds. Food Chemistry, 289, 404-412.

Petropoulos, S. A., Fernandes, Â., Tzortzakis, N., Sokovic, M., Ciric, A., Barros, L., \&
Ferreira, I. C. F. R. (2019a). Bioactive compounds content and antimicrobial activities of wild edible Asteraceae species of the Mediterranean flora under commercial cultivation conditions. Food Research International, 119, 859-868.

Petropoulos, S. A., Pereira, C., Barros, L., \& Ferreira, I. C. F. R. (2017). Leaf parts from Greek artichoke genotypes as a good source of bioactive compounds and antioxidants. Food and Function, 8(5), 2022-2029.

Petropoulos, S. A., Pereira, C., Ntatsi, G., Danalatos, N., Barros, L., \& Ferreira, I. C. F. R. (2018). Nutritional value and chemical composition of Greek artichoke genotypes. Food Chemistry, 267, 296-302.

Petropoulos, S. A., Pereira, C., Tzortzakis, N., Barros, L., \& Ferreira, I. C. F. R. (2018), Nutritional value and bioactive compounds characterization of plant parts from Cynara cardunculus L. (Asteraceae) cultivated in central Greece. Frontiers. Plant Science, 9, 459.

Pinela, J., Carvalho, A. M., \& Ferreira, I. C. F. R. (2017). Wild edible plants: Nutritional and toxicological characteristics, retrieval strategies and importance for today's society. Food and Chemical Toxicology, 110, 165-188.

Ramos, P. A. B., Guerra, Â. R., Guerreiro, O., Santos, S. A. O., Oliveira, H., Freire, C. S. R., ... Duarte, M. F. (2017). Antiproliferative effects of Cynara cardunculus L. var. altilis (DC) lipophilic extracts. International Journal of Molecular Sciences, 18, 63.

Ramos, P. A. B., Santos, S. A. O., Guerra, Â. R., Guerreiro, O., Freire, C. S. R., Rocha, S. M., ... Silvestre, A. J. D. (2014). Phenolic composition and antioxidant activity of different morphological parts of Cynara cardunculus L. var. altilis (DC). Industrial Crops and Products, 61, 460-471.

Salem, M. B., Affes, H., Athmouni, K., Ksouda, K., Dhouibi, R., Sahnoun, Z., ... Zeghal, K. M. (2017). Chemicals compositions, antioxidant and anti-Inflammatory activity of Cynara scolymus leaves extracts, and analysis of major bioactive polyphenols by HPLC. Evidence-Based Complementary and Alternative Medicine, 2017, 4951937.

Scavo, A., Pandino, G., Restuccia, C., Parafati, L., Cirvilleri, G., \& Mauromicale, G. (2019). Antimicrobial activity of cultivated cardoon (Cynara cardunculus L. var. altilis DC.) leaf extracts against bacterial species of agricultural and food interest. Industrial Crops and Products, 129, 206-211.

Vergara, P., Ladero, M., García-Ochoa, F., \& Villar, J. C. (2018). Pre-treatment of corn stover, Cynara cardunculus L. stems and wheat straw by ethanol-water and diluted sulfuric acid: Comparison under different energy input conditions. Bioresource Technology, 270, 449-456.

Zayed, A., Serag, A., \& Farag, M. A. (2020). Cynara cardunculus L.: Outgoing and potential trends of phytochemical, industrial, nutritive and medicinal merits. Journal of Functional Foods, 69, Article 103937. 